\title{
FRIOS Parameters, Key to Reduce Feto-Maternal Mortality in Pre-Eclampsia
}

\author{
Amita Sharma ${ }^{*}$, Archana Tiwari2, Pandey Kiran³, Agnihotri Meera ${ }^{3}$ \\ ${ }^{1}$ Department of Obstetrics and Gynecology, V. C. S. G. Govt Institute of Medical Sciences \& Research, Srinagar \\ Garhwal, Uttarakhand \\ ${ }^{2}$ Department of Biochemistry, Amity University, Noida, India \\ ${ }^{3}$ Department of Obstetrics and Gynecology, GSVM, Kanpur, India \\ Email: ${ }^{*}$ dramita99@gmail.com
}

Received 4 March 2014; revised 2 April 2014; accepted 9 April 2014

Copyright (C) 2014 by authors and Scientific Research Publishing Inc.

This work is licensed under the Creative Commons Attribution International License (CC BY).

http://creativecommons.org/licenses/by/4.0/

(c) (†) Open Access

\begin{abstract}
Objective(s): To evaluate the role of free radical induced oxidative stress in predicting, prevent and prompt management of pre-eclampsia. Method(s): This prospective study was conducted on 320 pregnant women of which 240 women with pregnancy induced hypertension taken as study group and 80 normal pregnant women were taken as control. Free radical status was evaluated by estimating lipid peroxidation product malonyladehyde and antioxidants-superoxide dismutase, catalase, glutathione reductase. Statistical analysis was done by using SPSS software. Result(s): Pre-eclampsia is significantly associated with free radical induced oxidative stress. Serum level of lipid peroxidation product malondialdehyde increased in pre-eclamptic women. Serum level of antioxidants SuperOxide Dismutase, Catalase level, Glutathione Reductase were reduced. Results are statistically significant. Conclusion(s): Free radical induced oxidative stress is increasing in pre-eclampsia and plays a critical role in etiopathogenesis of pre-eclampsia.
\end{abstract}

\section{Keywords}

Free Radical Induced Oxidative Stress (FRIOS); Pre-Eclampsia; Malondialdehyde; Superoxide Dismutase; Catalase; Glutathione Reductase

\section{Introduction}

Pre-eclampsia is the condition in which hypertension essentially complicates the pregnancy with albuminuria. It is a multisystemic disorder affecting virtually every organ and system. In India, hypertension complicates appro-

"Corresponding author. 
ximately $10 \%$ - 15\% pregnancies and is a major contributor to maternal and fetal mortality and morbidity [1]. Oxidative stress is defined as an imbalance between the cellular generation of reactive oxygen species (ROS) and capacity of antioxidants to prevent oxidative damage [2]. Free radicals are formed during all cellular metabolism conducting in body [3]. Lipid damage as a result of oxidative stress is quantified by measurement of malondialdehyde (MDA) [4]. Free radical production and biological oxidation can be seen in normal placental tissues, but this may not constitute oxidative stress as the balance is maintained by enhanced antioxidant activity [2]. Enzymatic antioxidants such as glutathione peroxidase (GSH), catalase (CAT), Superoxide dismutase (SOD) and non-enzymatic antioxidants such as uric acid, bilirubin, vitamins A, E and Ascorbic acid limit tissue concentrations of free radicals [5]. The imbalance between placental prooxidant and antioxidant forces in favour of prooxidant intensifies the release of lipid peroxidation into circulation leads oxidative stress and causes endothelial cell activation and dysfunction in preeclampsia [6]. This vascular contact with circulating peroxidation products causes dysfunction of vascular endothelium initiates the maternal pathological changes in pre eclampsia [3] [7] [8]. This study evaluated the role of FRIOS in PIH. In PIH, lipid peroxidation product malonaldehyde, increased and superoxide dismutase, catalase, glutathione reductase antioxidant enzyme decreased.

\section{Methods}

The prospective study was conducted on pregnant women admitted from at Upper India Sugar Exchange Maternity Hospital, GSVM, Kanpur. The study group consisted of 240 women admitted with diagnosis of preeclampsia. Control group consist of 80 women with normal natural conception with healthy pregnancy and healthy outcome. Inclusion criteria were Gestational age > 28 weeks, B.P. > 140/90 mm Hg, Urine protein > +1 dip stick test, and women with chronic hypertension, Intrinsic renal disease, liver disease, urinary tract infection, gestational diabetes mellitus, anemia, were excluded from study. Women from both control and study group were studied in detail with regard to the clinical history, general, abdominal, speculum and vaginal examination, routine investigations, ultrasonography (obs). Fasting blood samples were obtained from all groups to measure the level of oxidants and antioxidants. Lipid peroxidation product (malondialdehyde MDA)were estimated according to the modified method by Ohkawa et al. Serum level of superoxide dismutase (SOD)was determined by modified method of McCord and Fridovich, catalase (CAT) by method Aebi, glutathione reductase (GR) by spectrophotometrically. Statistical analysis of the data was done by using SPSS software. The results were expressed as mean \pm standard error. P value less than 0.05 was taken as statistically significant value.

\section{Results}

In our study, study group were included 240 pre-eclamptic pregnant women and control group were 80 normal pregnant women.

Table 1 shows mean age in control group was 22.85 years and in study group 24.14 years. $62.2 \%$ patients were primigravida in control group and $62.5 \%$ in study group. Mean gestational age in control group was 35.2 weeks and 34.95 weeks in study group. Systolic blood pressure and diastolic blood pressure in study group were $164 \pm 7.66 \mathrm{mmHg}$ and $102.5 \pm 5.53 \mathrm{mmHg}$ respectively. In control group, systolic blood pressure and diastolic blood pressure were $112.2 \pm 6.44 \mathrm{mmHg}$ and $72.2 \pm 4.84 \mathrm{mmHg}$ respectively.

Graphs show comparison of various enzymes in normal pregnancy and pre-eclamptic pregnancy. Graph 1

Table 1. Clinical parameters in control and study group.

\begin{tabular}{|c|c|c|c|c|c|c|}
\hline & \multicolumn{3}{|c|}{ Control Cases $\quad(n=80)$} & \multicolumn{3}{|c|}{ Study Cases $\quad(n=240)$} \\
\hline & Range & Mean & \pm S.D. & Range & Mean & \pm S.D. \\
\hline Age & 18 - 30 Years & 22.85 & 2.94 & 20 - 36 Years & 24.14 & 4.22 \\
\hline Parity & $62.2 \%$ Primi & 37.5\% Multi & 0\% Grand Multipara & $62.5 \%$ Primi & 35\% Multi & 2.5\% Grand Multipara \\
\hline Gestational Age & 12 - 38 Weeks & 35.2 & 1.91 & 12-38 Weeks & 34.95 & 3.04 \\
\hline SBP & $100-120 \mathrm{~mm} \mathrm{Hg}$ & 112.2 & 5.4 & $130-210$ mm Hg & 164 & 7.66 \\
\hline DBP & $64-82 \mathrm{~mm} \mathrm{Hg}$ & 72.2 & 5.2 & $90-100 \mathrm{~mm} \mathrm{Hg}$ & 102.50 & 5.53 \\
\hline
\end{tabular}


shows mean level of lipid peroxidation end product malondialdehyde were $8.8839 \pm 1.454 \mathrm{~mol} / \mathrm{ml}$ plasma in study group as compared to $4.614 \pm 1.323 \mathrm{~mol} / \mathrm{ml}$ plasma. This difference were highly significant $\mathrm{t}=16.25 p$ $(<0.001)$.

Level of Antioxidant enzymes were found to reduce significantly. Graph 2 and Graph 3 shows the mean level of superoxide dismutase which were noted as $0.3480 \pm 0.0774 \mathrm{unit} / \mathrm{mg}$ protein in study group as compared to $0.7876 \pm 0.1098$ units $/ \mathrm{mg} /$ protein, Catalase levels in study group $0.071 \pm 0.312 \mathrm{unit} / \mathrm{mg}$ protein in contrast to $0.2231 \pm 0.0829$ unit/mg protein in control group. Graph 4 shows mean level Glutathione Reductase levels in pre-eclamptic women $30.3786 \pm 5.378$ than $60.8930 \pm 6.201$ in normal pregnant women. The difference was statistically significant $p<0.01$.

\section{Discussion}

Lipid peroxidation has been shown to be of great importance in mammalian physiology and pathophysiology in

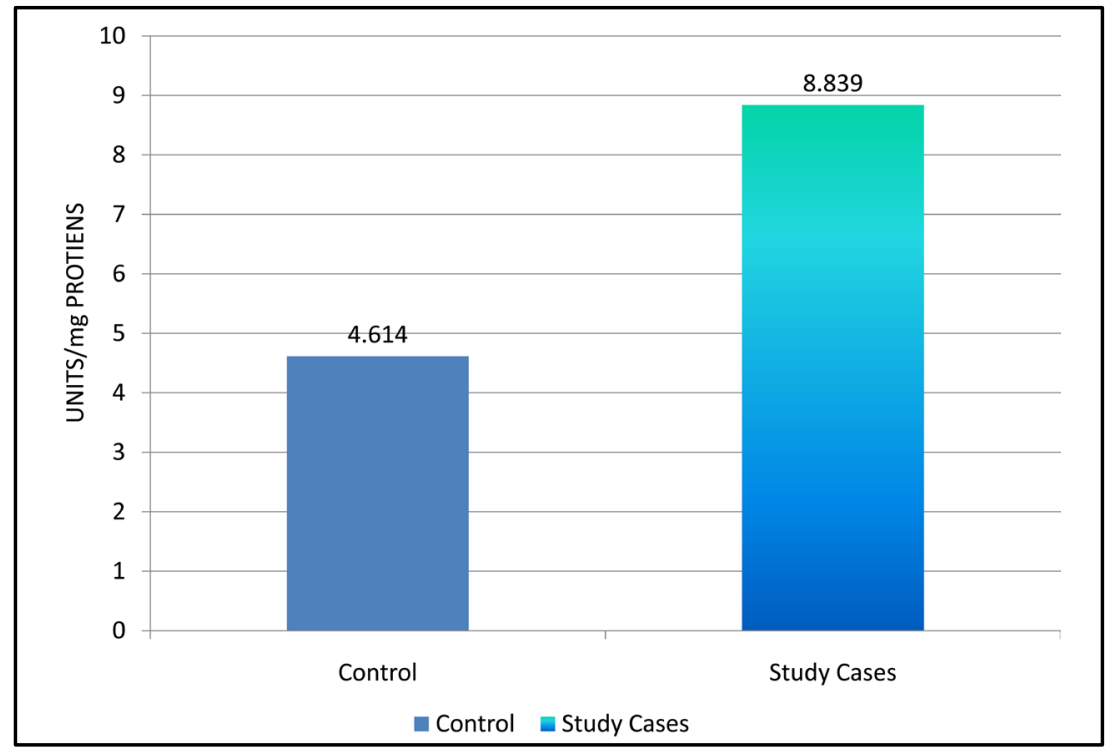

Graph 1. Comparative evaluation of MDA levels.

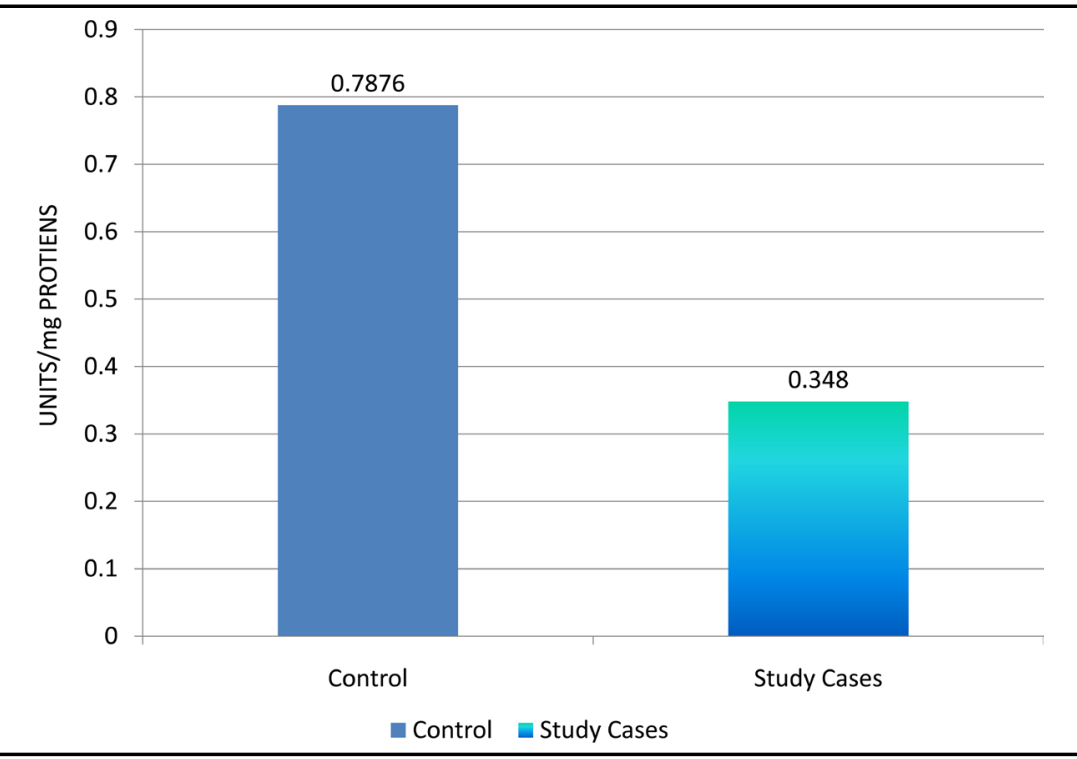

Graph 2. Comparative evaluation of SOD levels. 


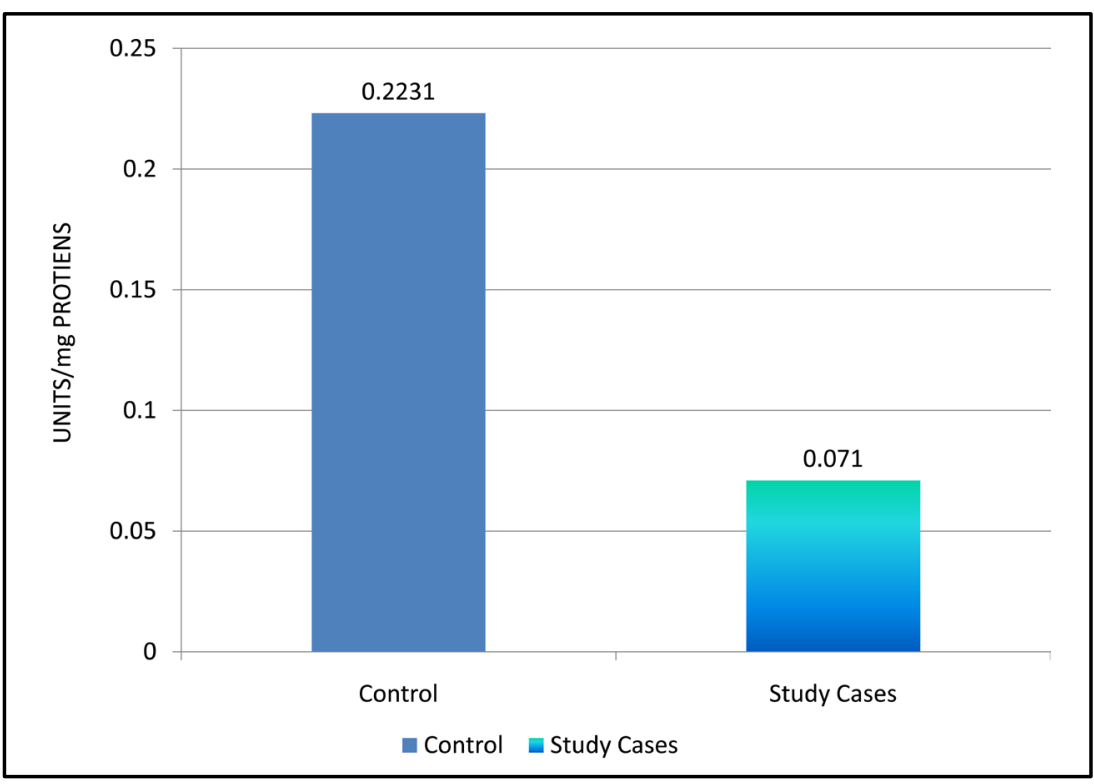

Graph 3. Comparative evaluation of CAT levels.

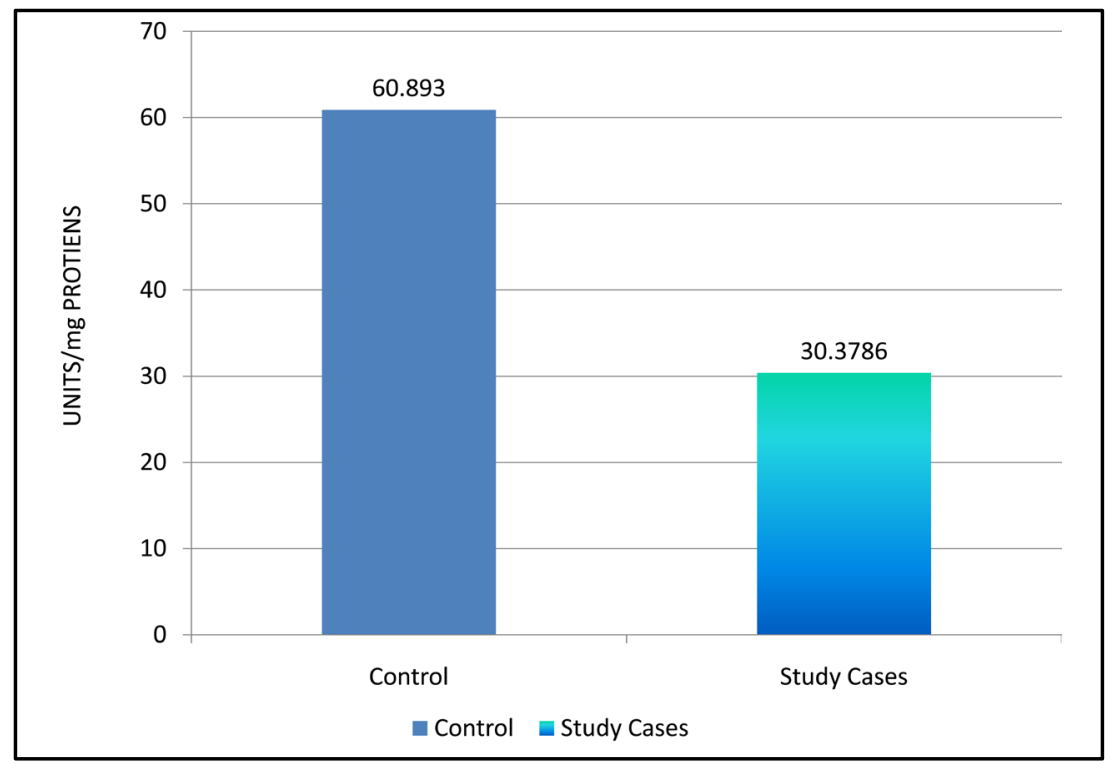

Graph 4. Comparative evaluation of GR levels.

the past three decades. It has been suggested that there is a deficiency in protective antioxidant systems or increased utilization of antioxidants in pre-eclampsia compared with normal pregnancy [9]. We found significant increase in MDA levels, an indicator of lipid peroxidation, in preeclampsia and eclampsia as compared to healthy pregnancy. In normal pregnancy lipid peroxidation also increased but in normal pregnancy to counteract this lipid peroxidation, there is simultaneous activation of antioxidant defense system. This phenomenon is not seen in women with pre-eclampsia. We found decreased serum GSH, SOD and catalase activity in preeclampsia and eclampsia as compared to normal pregnancy in this study.

Kumar and Das [10] showed that the activities of erythrocyte SOD and catalase were significantly decreased in women with preeclampsia compared to controls. Madazli R et al. [11] showed significant decreases in activities of placental SOD and GSH and increased catalase activity in the placenta of preeclamptic pregnancies compared to those of women with normal pregnancies. Sharma et al. [12] reported that erythrocyte SOD and CAT activity was markedly decreased in preeclamptic women compared to healthy pregnant women and non pregnant women. SOD 
scavenges the superoxide radical by catalyzing its dismutation into $\mathrm{H}_{2} \mathrm{O}_{2}$ and $\mathrm{O}_{2}$. CAT is located in Mitochondrial peroxisomes (MPO), and decomposes hydrogen peroxide $\left(\mathrm{H}_{2} \mathrm{O}_{2}\right)$ to water and oxygen. At low concentration most of the $\mathrm{H}_{2} \mathrm{O}_{2}$ is removed by glutathione peroxidase which itself is reduced in the form of glutathione reductase. But at higher concentration of $\mathrm{H}_{2} \mathrm{O}_{2}$ the catalase becomes important as it decomposes $\mathrm{H}_{2} \mathrm{O}_{2}$ and helps in its removal. Chamy VM et al. [13] and Patil SB et al. [14] reported Free radical oxidative stress followed by tissue insult which is being compensated by SOD in conjunction with catalase and glutathione reductase that removes $\mathrm{H}_{2} \mathrm{O}_{2}$ from the human cells

\section{Conclusion}

Free radical induced oxidative stress has a critical role in etiopathogenesis of Pre-eclampsia and toxemia of pregnancy. We can predict pre-eclampsia, a major cause of maternal morbidity and mortality by measuring FRIOS.

\section{References}

[1] Berg, C.J., Atrash, H.K., Koonin, L.M. and Tucker, M. (1996) Pregnancy Related Mor Detection of Significant Proteinurea in Pregnant Women with Suspected Preeclampsiatality in the United State (1987-1990). Journal of Obstetrics \& Gynaecology, 88, 161-165. http://dx.doi.org/10.1016/0029-7844(96)00135-4

[2] Perkins, A.V. (2006) Endogenous Antioxidants in Pregnancy and Preeclampsia. Australian and New Zealand Journal of Obstetrics and Gynaecology, 46, 77-83. http://dx.doi.org/10.1111/j.1479-828X.2006.00532.x

[3] Mac Donald-Wicks, L.K. and Garg, M.L. (2002) Modulation of Carbon Tetrachloride-Induced Oxidative Stress by Dietary Fat in Rats. The Journal of Nutritional Biochemistry, 13, 87-95. http://dx.doi.org/10.1016/S0955-2863(01)00199-1

[4] Serdar, Z., Gur, E., Develioglu, O., Colakogullari, M. and Dirican, M. (2002) Placental and Decidual Lipid Peroxidation and Antioxidant Defenses in Pre-Eclampsia. Lipid Peroxidation in Pre-Eclampsia. Pathophysiology, 9, 21-25. http://dx.doi.org/10.1016/S0928-4680(02)00052-4

[5] Noyan, T., Tahin, I., Sekeroglu, M.R. and Dulger, H. (2003) The Serum Vitamin C Levels in Behcet's Disease. Yonsei Medical Journal, 44, 771-778.

[6] Bowen, R.S., Moodley, J., Dutton, M.F. and Theron, A.J. (2001) Oxidative Stress in Pre-Eclampsia. Acta Obstetricia et Gynecologica Scandinavica-Wiley Online Library, 80, 719-725. http://dx.doi.org/10.1034/j.1600-0412.2001.080008719.x

[7] Gitto, E., Retter, R.J., Karbownik, M., et al. (2002) Causes of Oxidative Stress in the Pre- and Perinataln Period. Biological Neonate, 81, 146-157. http://dx.doi.org/10.1159/000051527

[8] Harsem, N.K., Braekke, K. and Staff, A.C. (2005) Augmented Oxidative Stress as Well as Antioxidant Capacity in Maternal Circulation in Pre-Eclampsia. European Journal of Obstetrics \& Gynecology and Reproductive Biology, 45, 456-467.

[9] Tastekin, A., Ors, R., Demircan, B., Saricam, Z., Ingec, M. and Akcay, F. (2005) Oxidative Stress in Infants Born in Pre-Eclamptic Mothers. Pediatrics International, 47, 658-662. http://dx.doi.org/10.1111/j.1442-200x.2005.02146.x

[10] Kumar, C.A. and Das, U.N. (2000) Lipid Peroxides, Antioxidants and Nitric Oxide in Patients with Preeclampsia and Essential Hypertention. Medical Science Monitor, 6, 901-907.

[11] Madazli, R., Benian, A., Aydin, S., Uzun, H. and Tolun, N. (2002) The Plasma and Placental Levels of Malondialdehyde, Glutathione and Superoxide Dismutase in Pre-Eclampsia. Journal of Obstetrics \& Gynaecology, 22, 477-480. http://dx.doi.org/10.1080/0144361021000003573

[12] Sharma, J.B., Sharma, A., Bahadur, A., Vimala, N., Satyam, A. and Mittal, S. (2006) Oxidative Stress Markers and Antioxidant Levels in Normal Pregnancy and Pre-Eclampsia. International Journal of Gynecology \& Obstetrics, 94, 23-27. http://dx.doi.org/10.1016/j.ijgo.2006.03.025

[13] Chamy, V.M., Lepe, J., Catalán, A., Retamal, D., Escobar, J.A. and Madrid, E.M. (2006) Oxidative Stress Is Closely Related to Clinical Severity of Pre-Eclampsia. Biological Research, 39, 229-236. http://dx.doi.org/10.4067/S0716-97602006000200005

[14] Patil, S.B., Kodliwadmath, M.V. and Kodliwadmath, M. (2009) Lipid Peroxidation and Antioxidant Activity in Complicated Pregnancies. Clinical and Experimental Obstetrics and Gynecology, 36, 110-112. 